\title{
Evaluate Urban Resilience in Light of Water Resources and Identify Critical Driving Factors-a Case Study from the Yangtze River Economic Belt's Lower Reaches
}

\section{Min An}

China Three Gorges University

Mengfei Song ( $\boldsymbol{\nabla}$ songmengfei@ctgu.edu.cn )

China Three Gorges University https://orcid.org/0000-0003-4154-0137

\section{Weijun He}

China Three Gorges University

Jin Huang

China Three Gorges University

\section{Xue Fang}

China Three Gorges University

\section{Research Article}

Keywords: Urban resilience, Spatial heterogeneity, Geographic detectors, RAGA-PP, Water resources, Driving factors

Posted Date: January 28th, 2022

DOI: https://doi.org/10.21203/rs.3.rs-1191194/v1

License: (c) (i) This work is licensed under a Creative Commons Attribution 4.0 International License.

Read Full License 


\title{
Evaluate Urban Resilience in Light of Water Resources and Identify Critical Driving Factors-a Case Study from the Yangtze River Economic Belt's lower reaches
}

\author{
Min Anª, Mengfei Song ${ }^{\mathrm{a}}$, Weijun $\mathrm{He}^{\mathrm{a}}$, Jin Huang ${ }^{\mathrm{a}, \mathrm{b}^{*}}$, Xue Fang ${ }^{\mathrm{a}}$
}

a. College of Economics \& Management, China Three Gorges University, No.8, University Avenue, Yichang, P.R. China. anmin@ ctgu.edu.cn (M.A.); songmengfei@ ctgu.edu.cn (M.S.); 616614429@qq.com (W.H.); fangxue@ctgu.edu.cn (X.F.).

b. Humanities and Social Sciences in Colleges and universities of Hubei Province (Research Centre for Reservoir Resettlement, China Three Gorges University), China Three Gorges University, No.8, University Avenue, Yichang, P.R. China. huangjin@ctgu.edu.cn (J.H.).

(*Corresponding Author)

\section{Abstract}

The acceleration of urbanization created a series of problems such as water shortage crisis and serious water pollution which brought the vulnerability of urban water resources, thus affected the economic and social development of city and increased risk of external impact on the urban system. Therefore, improving urban resilience (UR) from the viewpoint of water resources plays an essential role in resisting external shocks. Our paper based on 21 cities along the Yangtze River Economic Belt's (YREB) lower reaches relevant data from 2010 to 2018, constructs a new UR evaluation framework of "Economy-Society-Infrastructure-Water Resources". Then the Projection Pursuit Evaluation Model of Real Coding based on Accelerating Genetic Algorithm (RAGA-PP) is used to measure the UR scientifically, Geographic Detectors (GD) method detected and analyzed the UR driving factors. The results present that: (1) The general level of UR in study area was low and characterized by attenuation from central cities to marginal cities, among them Shanghai is the highest (0.651), while Chizhou is the lowest (0.178). The resilience of cities along the YREB's lower reaches shows a downward trend. (2) Compared with the UR without considering water resources, the UR from the perspective of water resources is relatively higher. Which means that cities along the YREB's lower reaches have enhanced their ability to deal with external pressure and impact from the perspective of water resources. (3) Water resources and Infrastructure were two factors affected the spatial diversity of UR along the YREB's lower reaches in 2018 and their average explanatory power of factors increased by $30.610 \%$ and $139.035 \%$ respectively; the explanatory power of Economy (5.270\%) and Society (1.342\%) were relatively smaller. With these findings our paper provides relevant suggestions to enhance UR along the YREB's lower reaches from the perspective of water resources.

Keywords Urban resilience; Spatial heterogeneity; Geographic detectors; RAGA-PP; Water resources; Driving factors

\section{Introduction}

City as a complex system, gathers various advantageous resources, runs a variety of economic activities and carries millions of people. The population, resources, and economic activities promote the prosperity and develop the city while also have an impact on the sustainable development with the 
changes of external environment. For example, human activities aggravate urban environmental pollution (Zhao et al., 2019), ignore economic risks leading to economic crisis (Bjornskov, 2016), natural environment and human activities increased flood and drought disasters (Cabezon et al., 2015; Yan et al., 2012; Yin, 2020). Urban resilience (UR) is an ability that city can digest and absorb external shocks, as well as preserve its original main characteristics, structure and key functions (Meerow et al., 2016). Nevertheless, cities are facing increasingly serious problems along with the speeding up of industrialization and urbanization. How to improve the cities' resilience to resist external shocks and minimize the negative impact of outside world on their own system is one of the common problems faced by urban development all over the world. Therefore, it is essential to measure UR and analyze its critical influence factors scientifically, which can help us understand the degree of UR withstand risks and clarify the reasons that may cause threats.

Researchers establishes different UR index systems from multi-dimensional perspective to measure UR deeply. Martin, Zhou et al. and Rose et al. all constructed an indicator system of economic resilience from the perspective of economic shocks (Martin and Gardiner, 2019; Rose, 2004; Zhou et al., 2020); Abdul et al. set up a social resilience indicator system to enhance disaster management (Abdul Majeed et al., 2018; Abdul Majeed et al., 2020; Cutter et al., 2008). Nevertheless, some other scholars have established an inclusive system for evaluating urban disaster resilience from the four aspects: Ecological environment, Economy, Society and Infrastructure services (Ma et al., 2020). Through above analysis, we found that scholars had constructed UR analysis framework from five aspects: Economy, Society, Infrastructure, Ecology and Disasters, these dimensions were decided by the characteristics of the research objects. But the research perspective had gradually shifted from single disciplines, such as disaster management and urban planning, to multidisciplinary and integrated research. Especially as water resources have become an important resource endowment of cities, scholars have begun to pay more attention to integrate water resources to UR (Won et al., 2014; Zhang et al., 2019), especially water quality management.

Cities along rivers are born and prospered by water. Water resources are the key restrictive resource for urban sustainable development (Fang and Xie, 2010). Cities sustainable development requires a moderate amount of water resources. Lake of water restricts the development of the city's economy and water resources exceeding the city's carrying capacity also threatens its operation. China Flood and Drought Disaster Bulletin in 2019 presents that, 47.67 million people were affected by floods in China, as well as economic losses reach 192.27 billion yuan, while urban droughts give rise to the loss of economy directly, achieving 14.932 billion yuan. Water greatly restricted the sustainable development of cities. At the same time, urban system has a greater impact on the water system. In particular, cities along river basins always had rapid accumulation of population and wealth, but the risks related to water resources also increased sharply (Du et al., 2018; Li et al., 2016). Therefore, scientifically measuring the resilience of cities along the river can put target suggestions to enhance the resilience of cities continuously.

From above analysis, we found that UR system with considering water resources should be a complex system composed of multiple different dimensions. Proper methods need to be used. Among the existing evaluation methods of UR, some scholars have made a qualitative analysis on the practical process of resilient cities (Masnavi et al., 2019; Xu et al., 2021), but the lack of related statistics and indicators makes it not intuitive and accurate to describe UR. Monte Carlo Analytic Hierarchy Process 
(MCAHP) and Analytic Hierarchy Process (AHP) are used respectively to analyze urban flood risk factors (Koc and Isik, 2021; Moghadas et al., 2019). Although these two methods use quantitative analysis, it is not scientific enough to evaluate UR because that the subjectivity caused by human interference factors makes the index ranking values different. There are also studies that have constructed an entropy weight model (Zhang et al., 2021) and a PCA (principal component analysis) method (Wu, 2021) to evaluate the level of UR. Even these two objectively analyze the impact of system data with high dimensional, nonlinear and non-normality on the UR to a certain extent, the correlation between different systems was ignored. Our paper constructed a multi-dimensional and non-linear UR index system (IS) and its subsystems are interrelated. In order to avoid the correlation between systems affecting the objectivity of the results, our paper selects the projection pursuit evaluation model of real coding based on Accelerating Genetic Algorithm (RAGA-PP), which can measure from global optimization with considering index related and can scientifically measure the multi-dimensional UR evaluation system.

Compared with UR measurement, identifying the key factors that affect the UR level can provide the government with targeted suggestions to effectively improve the UR level. There are more and more researches used different methods to find the driving factors of UR. Some scholars use spatial measurement models (Zhang et al., 2019), DPSIR model (Drive-Pressure-State-Impact-Response) (Zhao et al., 2021), Obstacle model (Cui et al., 2021) and so on to discuss the driving factors of UR. However, the spatial measurement model mainly calculates the spatial dependence through the impact of the behavior of adjacent areas on the central areas and then judges the driving factors. The DPSIR model and the Obstacle degree model study the spatial driving factor value or the negative impact value of a single index on the research object. Above methods ignore the spatial differences within the region and do not consider the spatial heterogeneity between various indicators. The geographic detectors (GD) make up for the deficiencies of the research, because the method is a powerful tool to find critical driving factors with consider spatial heterogeneity and spatial dependence.

Above all, we found three research gaps. Firstly, UR is multi-dimensional, but most of the relevant researches are based on a single or comprehensive assessment which includes economic level, social development, infrastructure, and ecology, without considering that cities along rivers are also affected by water resources. Therefore, the construction of the UR evaluation system needs to be expanded from the perspective of water resources. Secondly, the UR system has the characteristics of multi-dimensional nonlinearity and inter-system interrelationship. Most of the current measurement of UR does not fit the feature well. Finally, the research areas in our paper have spatial heterogeneity, but current research seldom considered the characteristics when study impact factors.

To fill above research gaps, our study takes 21 cities along the Yangtze River Economic Belt's (YREB) lower reaches as the research object, and based on relevant data from 2010 to 2018, firstly constructs an evaluation IS for UR of "Economy-Society-Infrastructure-Water Resources"; Secondly, RAGA-PP is used to evaluate the UR and make the spatial-temporal evolution analysis, and GD is applied to explore the resilience's driving factors. We also provide targeted suggestions to develop the cities' resilience in the YREB and to enhance the urban system's resistance.

\section{Study region}

The YREB's lower reaches pass through Shanghai, Jiangsu, Zhejiang and Anhui, including 21 cities. 
Its area is about 350,300 square kilometers, accounting for $17.1 \%$ of the YREB (as shown in Fig. 1). As the economic center of the YREB, the GDP of the cities along the lower reaches in 2018 was 21.15 trillion-yuan, and the proportion is 52\% of YREB's total GDP. Moreover, cities along the lower reaches have always been traditionally densely populated areas in China. In 2018, there were about 225 million people in the lower reaches, accounting for $37.6 \%$ of the total population of the YREB. It indicates that the lower reaches are facing huge regional population and economic pressure.

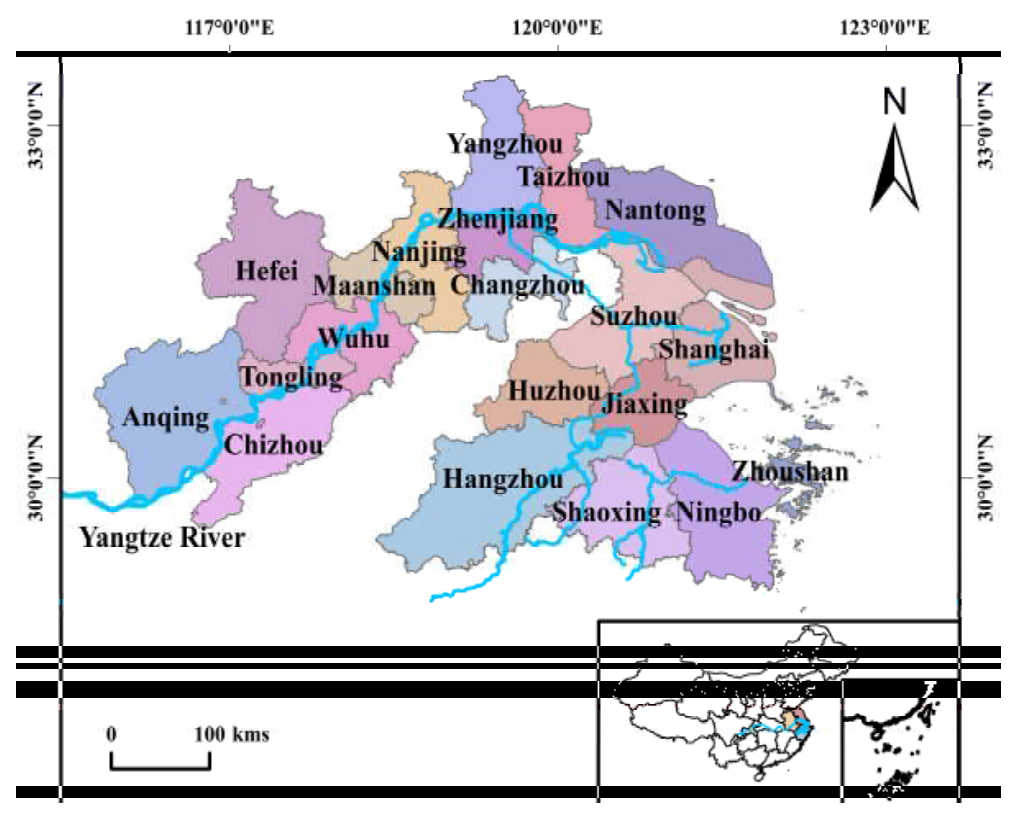

At the same time, Shanghai, Jiangsu, Zhejiang, and Anhui are adjacent to the Yangtze River. China Flood and Drought Disaster Bulletin states clearly, Anhui and Zhejiang are the areas with the most direct economic losses caused by floods from 2014 to 2018, worth 117.10 billion-yuan, with $22.12 \%$ of YREB. In 2019, the coverage of influence caused by the drought was expanding and its extent continued to increase. Therefore, it is critical to analyze the resilience level of cities along the YREB's lower reaches and explore its driving factors to improve their ability withstand risks, which is of very important strategic for the high-quality evolution of cities in the YREB.

\section{Methodology}

\section{Construction of Indicator System}

UR means the cities' ability to pull through, adapt and develop when facing any sustained chronic pressure or sudden disaster (Shamsuddin, 2020). It's usually the result of the combined effect of many factors, such as economic development, social security, resources scarce, infrastructure improvement and so on. Base on this the UR index evaluation system can be composed of Economy, Society, Infrastructure and Water Resources. First of all, economic resilience is the fundament of UR. It is the ability of cities to maintain a stable life and production after an economic shock. The change of GDP not only has a crucial impact on various urban economic activities and residents' lives, but also provides economic security and financial support for urban society, infrastructure and water resources subsystems. Secondly, social resilience often repairs to communities or groups' power of dealing with exoteric pressure which is brought by social and political changes (Adger, 2000). A perfect social service system can ensure the 
infrastructure conditions of residents' life, promote the development of water resources system, and provide labor and technical support for economic development. Thirdly, infrastructure resilience is urban infrastructure systems' capability of recovering quickly and effectively from external shocks (Childers et al., 2015). A high level of urban infrastructure services can form a highly resilient system, which supports the city's economy, society and water resources. Finally, there is a complex relation both urban water resources and socio-economic comprehensive development (Zhu et al., 2020), a good water resources system can not only provide a good resource environment for the economy and society, but also promote each other with the infrastructure subsystem and the development of UR. Based on this, our paper established an IS based on "Economy-Society-Infrastructure-Water Resources". The relationship between the four dimensions is shown in Fig. 2.

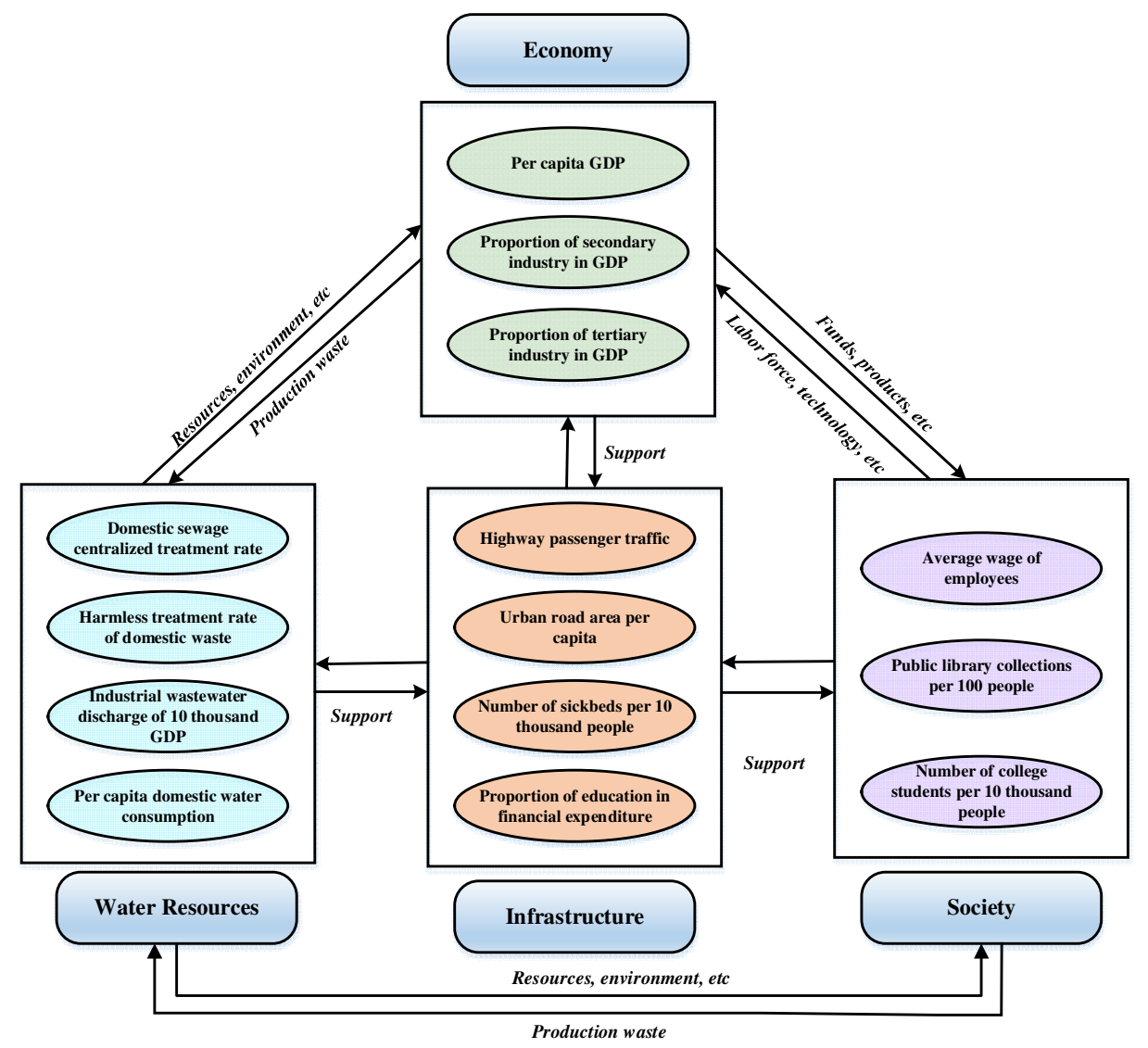

Fig. 2 Relationship of IS

Urban economic level is the core indicator of UR. At present, scholars mostly use GDP to measure it, but a single indicator is not enough and the information covered by multi-indicator evaluation often more comprehensive (Davies, 2011). Economic resilience used to be self-adaptability and ability to resist risks. Among them, self-adaptability is the ability to integrate social resources, maintain life and production stability after a region suffers an economic shock which can be expressed in terms of per capita GDP (Xin et al., 2019). While the ability to withstand risks aims at the capability of the regional economic system resists interference and absorbs shocks after facing economic shocks or disturbances, which is reflected in the proportion of secondary industries (SI) and tertiary industries (TI) in GDP (Tan et al., 2017).

The level of social resilience is nearly associated with the basic lives of the people. The society 
evaluation index of UR designed by Institute of University of California Berkeley emphasizes that community organizations can realize pre disaster response, mutual assistance in disaster process and post disaster self-recovery by enhancing social integration. Therefore, when calculate UR in society dimension should divided into three aspect: regional economic capacity, community participation capacity and socio demographic capacity (Li, 2021). Based on this, our paper selects three index to characterize social resilience: regional economic capacity, community participation capacity and social population capacity, which includes the average salary of employees, the collection of books in 100 public libraries and the number of college students per 10 thousand people.

Urban infrastructure is primarily reflected in the city's ability to provide a shelter and evacuation for men in crisis (Goncalves and Ribeiro, 2020). Therefore, our paper measures the resilience of urban infrastructure from four aspects: per capita road area, road passenger volume, sickbeds per 10 thousand people and the proportion of education expenditure in financial expenditure. Among them, the per capita road area and road passenger volume reflect the traffic accessibility of the city. The number of sickbeds per 10000 people and the proportion of education expenditure in financial expenditure reflect the emergency medical services and talent export that health institutions and educational institutions can provide in the event of a disaster.

UR of water resources used to be mainly reflected in the low pollutant treatment rate and high water pressure (Yang et al., 2021b). It will increase the load of water resources system, resulting in the degradation of urban water resources system function and reduce UR. Therefore, our paper measures the resilience of urban water resources from four aspects: domestic sewage centralized treatment rate, harmless treatment rate of domestic waste, industrial wastewater discharge of 10 thousand GDP and per capita domestic water consumption. IS is presented in Table 1.

\begin{tabular}{|c|c|c|c|c|c|}
\hline $\begin{array}{l}\text { Target } \\
\text { layer }\end{array}$ & $\begin{array}{l}\text { Criteri } \\
\text { on layer }\end{array}$ & Index layer & Index significance & $\begin{array}{l}\text { attribu } \\
\text { te }\end{array}$ & Unit \\
\hline \multirow{8}{*}{$\begin{array}{l}\text { Urban } \\
\text { resilience }\end{array}$} & \multirow{3}{*}{$\begin{array}{l}\text { Econom } \\
\mathrm{y}\end{array}$} & Per capita GDP(A1) & $\begin{array}{l}\text { Per capita economic } \\
\text { strength }\end{array}$ & + & $\begin{array}{l}\text { Ten } \\
\text { thousand yuan }\end{array}$ \\
\hline & & Proportion of SI in GDP(A2) & $\begin{array}{l}\text { Secondary industrial } \\
\text { structure }\end{array}$ & + & $\%$ \\
\hline & & $\begin{array}{l}\text { Proportion of TI in GDP } \\
\text { (A3) }\end{array}$ & Tertiary industry structure & + & $\%$ \\
\hline & \multirow{3}{*}{ Society } & $\begin{array}{l}\text { Average wage of employees } \\
\text { (A4) }\end{array}$ & Resident wage income & + & Yuan \\
\hline & & $\begin{array}{l}\text { Public library collections per } \\
100 \text { people(A5) }\end{array}$ & $\begin{array}{c}\text { Guarantee level of public } \\
\text { resources }\end{array}$ & + & $\begin{array}{l}\text { Book / } 100 \\
\text { people }\end{array}$ \\
\hline & & $\begin{array}{l}\text { Number of college students } \\
\text { per } 10 \text { thousand people (A6) }\end{array}$ & Urban education level & + & Person \\
\hline & \multirow{2}{*}{$\begin{array}{c}\text { Water } \\
\text { Resources }\end{array}$} & $\begin{array}{c}\text { Domestic sewage } \\
\text { centralized treatment rate } \\
\text { (A7) }\end{array}$ & Sewage treatment & + & $\%$ \\
\hline & & $\begin{array}{l}\text { Harmless treatment rate of } \\
\text { domestic waste (A8) }\end{array}$ & $\begin{array}{l}\text { Environmental } \\
\text { improvement }\end{array}$ & + & $\%$ \\
\hline
\end{tabular}


Industrial wastewater

discharge of 10 thousand GDP

(A9)

\begin{tabular}{|c|c|c|c|c|}
\hline & $\begin{array}{l}\text { Per capita domestic water } \\
\text { consumption (A10) }\end{array}$ & Residential water use & - & Ton \\
\hline \multirow{4}{*}{$\begin{array}{l}\text { Infrastr } \\
\text { ucture }\end{array}$} & $\begin{array}{l}\text { Highway passenger traffic } \\
\text { (A11) }\end{array}$ & Traffic facilities & + & $\begin{array}{c}\text { Ten } \\
\text { thousand } \\
\text { people }\end{array}$ \\
\hline & $\begin{array}{l}\text { Urban road area per capita } \\
\qquad(\mathrm{A} 12)\end{array}$ & Infrastructure construction & + & $\mathrm{m} 2$ \\
\hline & $\begin{array}{l}\text { Number of sickbeds per } 10 \\
\text { thousand people (A13) }\end{array}$ & Urban medical facilities & + & Set \\
\hline & $\begin{array}{l}\text { Proportion of education in } \\
\text { financial expenditure(A14) }\end{array}$ & Urban basic education & + & $\%$ \\
\hline
\end{tabular}

$197 \quad$ Note: in the table "+" represents positive indicators and "-" represents negative indicators.

\section{Data Sources}

199 Our research data are mainly from the statistical yearbooks, Statistical Bulletin of National Economic

200 and Social Development, Bulletin of Water Resources of 21 cities along the YREB's lower reaches from

$201 \quad 2009$ to 2019.

\section{RAGA-PP}

203 The projection pursuit model was proposed by American scientist Kruscal in the 1970s and it's the 204 most robust and practical method to solve the correlation between high-dimensional, non-normal and nonlinear data (Wu, 2021). Its main thought is that the statistics can be projected from the space of highdimension into low-dimension, and features of high-dimensional data will also be researched based on the dispersion structure of projection statistics with low-dimension (Deyou et al., 2013). What's more, the search and optimization function of traditional genetic algorithm gradually weakens with the increase of evolutionary iterations, resulting in the failure to form a global optimal goal in the process of practical application. However, there is a method named the Real Coding based on Accelerating Genetic Algorithm (RAGA). It can be used to figure out global optimization problem with high-dimension (Wei et al., 2012), which simulates the mechanism of survival of the fittest and chromosome information exchange within the population. There is no nonlinear relationship among the four subsystems of "Economy-Society-Infrastructure-Water Resources", and they are interrelated in the UR evaluation

215 system established in our paper. Therefore, the RAGA-PP suits our research problem well. The method specific flow chart is shown in Fig. 3. 


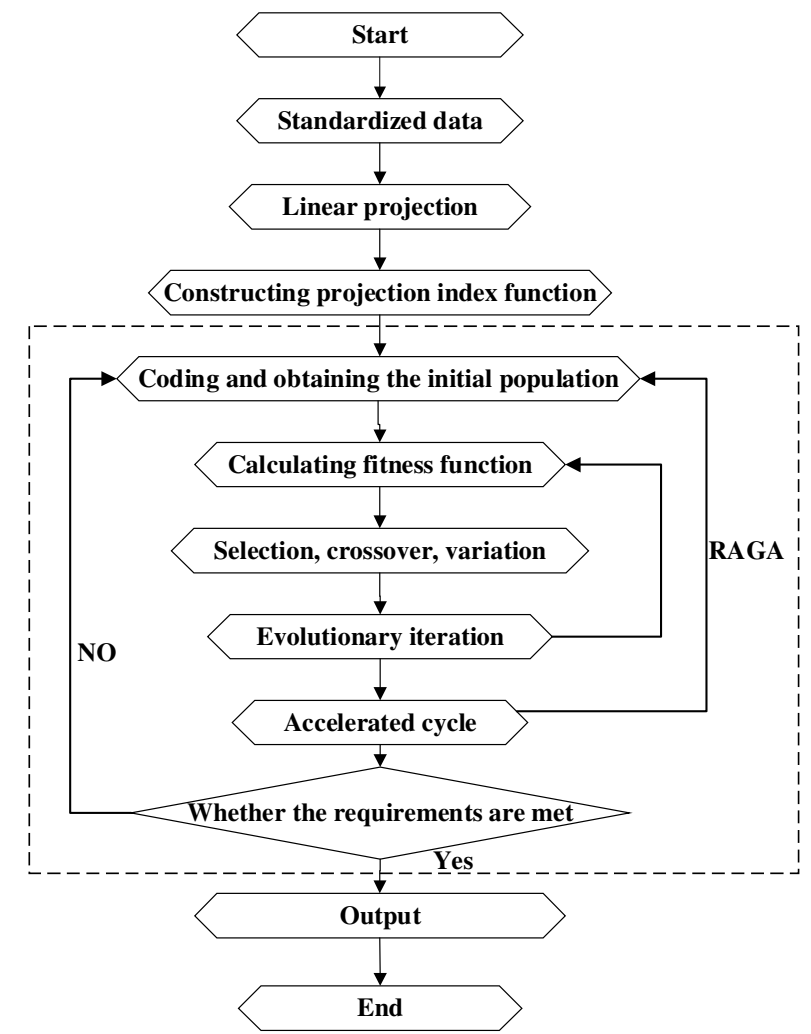

Fig. 3 The procedures of RAGA-PP Model

(1) Dimensionless data processing

In order to get rid of the dimensional difference and make the index's variation range unified, they are normalized:

For positive indicators:

$$
x_{i j}=\left(x_{i j}^{*}-x_{j \min }\right) /\left(x_{j \max }-x_{j \min }\right) \quad i=1, \mathrm{~L}, m ; j=1, \mathrm{~L}, n
$$

For negative indicators:

$$
x_{i j}=\left(x_{j \max }-x^{*}{ }_{i j}\right) /\left(x_{j \max }-x_{j \min }\right) i=1, \mathrm{~L}, m ; j=1, \mathrm{~L}, n
$$

In the above formula, $m$ is the number of cities; $n$ is the number of indexes; $x_{i j}^{*}$ is the $\mathrm{j}$-th index value of the i-th city; $x_{i j}$ is the index value after range normalizing; $x_{j \max } 、 x_{j \min }$ are the maximum and minimum of the $\mathrm{j}$-th index respectively.

(2) Construction of projection eigenvalue function

By synthesizing the $m$ dimensional data $x(i, j)$ into a dimension of projection $z_{i}$ with $a$ as the projection direction, and the projection eigenvalue $z_{i}$ of $x_{i j}$ can be expressed as:

$$
z_{i}=\sum_{j=1}^{n} a_{j} x_{i j}
$$


$z_{i}=a_{j} x_{i j}$ is regarded as the projection component value of sample $i$ index $j$, where $a$ is the vector with unit length.

(3) Constructing projection index function

Let $S(a)$ be the standard deviation of the projection value and $D(a)$ be the local density of the projection value, then the function of projection index is:

$$
Q(a)=S(a) \cdot D(a)
$$

$$
S(a)=\sqrt{\frac{\sum_{i=1}^{m}\left(z_{i}-E(\mathbf{z})\right)^{2}}{m-1}}
$$

$$
D(\mathrm{a})=\sum_{i=1}^{m} \sum_{j=1}^{m}\left(R-r_{i j}\right) \cdot f\left(R-r_{i j}\right)
$$

Above formula shows, $E(z)$ is the mean of comprehensive eigenvalue $z_{i}^{*} ; r_{i j}$ is the distance between $Z_{i}$ and $Z_{f}$, that is $r_{i f}=\left|z_{i}-z_{f}\right| ; \quad R$ is the window radius of density, it is usually taken as $0.1 S(a)$ (Li and Wang, 2020); $f\left(R-r_{i j}\right)$ is the unit step function, while $R-r_{i j} \geq 0$, the value is 1 , if not the value is 0 .

(4) Optimized projection index function

Diverse projection directions present various statistics structure features, and the best projection direction means that it is possible to reveal some feature structure of data with high-dimension. Then, the optimal projection direction will be evaluated through dealing with the problem that make the function of projection index reach maximum, that is:

$$
\max Q(a)=S(a) \cdot D(a)
$$

$$
\text { s.t } \sum_{j=1}^{n} a_{j}^{2}=1
$$

This is a nonlinear optimization problem, which is very sophisticated with $a^{*}$ as the optimization variable. Our research selects the genetic algorithm (Aydemir et al., 2003) first proposed by Professor Holland of the University of Michigan and the continuously improved RAGA (Fu et al., 2003). Then, according to the formulas ( $1 \sim 8$ ), our paper processes data using Matlab 2020b, and selects the population size is $N=400$, crossover probability is $P_{\mathrm{c}}=0.8$, variation probability is $P_{\mathrm{m}}=0.2$, the number of optimization variables $n=n_{X}$, the random number required for variation direction is $M=10$, and times of accelerating are 7.

(5) Priority arrangement

After substituting the best projection direction $a^{*}$ calculated by RAGA, the projection value $z_{i}^{*}$ of each sample point can be obtained, that is, the comprehensive ability of UR.

\section{GD}

Along with the advancement of geographic information system, GD has been developed. It is a kind of method which can be applied to detect spatial heterogeneity and disclose its drivers (Wang and Xu, 2017), whose key idea is if the research variables have an essential impact on the studied variables, they should have similar spatial distribution. In our study, due to the spatial stratification heterogeneity 
between the study areas and the spatial difference between the action intensity of factors, GD can be used to quantitatively analyze the single factor driving force and detect the main driving factors. In the study, statistics $\mathrm{q}$ is measured so as to study and analyze Y's spatial differentiation and the degree to which $\mathrm{X}$ interprets $Y^{\prime}$ 's spatial differentiation. The formula is as follows.

$$
q=1-\frac{\sum_{h=1}^{L} N_{h} \sigma_{h}^{2}}{N \sigma^{2}}
$$

In the formula, $h=1, \mathrm{~L}, L$ is Y's or X's stratification, $N_{h}$ and $N$ are the number of units in layer $h$ and the whole area respectively, $\sigma_{h}^{2}$ and $\sigma^{2}$ are the number of units in layer $h$ and Y's variance in the whole region, the range of $q$ is $[0,1]$ 。

Based on the GD model, our paper uses R software to analyze the calculated data, so as to obtain the drivers of UR along the YREB's lower reaches.

\section{Results}

\section{Overall characteristics}

According to the index data of 21 cities along the YREB's lower reaches from 2010 to 2018, the corresponding UR values are calculated by the RAGA-PP model and descriptive statistical analysis is carried out, which is depicted in Table 2.

\section{Table 2 Descriptive statistics of UR along the YREB's lower reaches}

\begin{tabular}{|c|c|c|c|c|c|c|c|c|c|}
\hline Statistics & 2010 & 2011 & 2012 & 2013 & 2014 & 2015 & 2016 & 2017 & 2018 \\
\hline Average & $\begin{array}{l}0.43 \\
1\end{array}$ & 0.402 & 0.396 & 0.396 & 0.480 & 0.406 & 0.359 & 0.355 & 0.350 \\
\hline $\begin{array}{l}\text { Standard } \\
\text { deviation }\end{array}$ & $\begin{array}{l}0.15 \\
1\end{array}$ & 0.130 & 0.138 & 0.133 & 0.139 & 0.149 & 0.169 & 0.161 & 0.143 \\
\hline $\begin{array}{l}\text { Coefficie } \\
\text { nt of } \\
\text { Variation }\end{array}$ & $\begin{array}{l}0.35 \\
0\end{array}$ & 0.324 & 0.349 & 0.335 & 0.289 & 0.368 & 0.470 & 0.454 & 0.407 \\
\hline Kurtosis & $\begin{array}{l}2.58 \\
7\end{array}$ & 3.449 & $\begin{array}{c}- \\
0.407\end{array}$ & 2.972 & $\begin{array}{c}- \\
0.919\end{array}$ & $\begin{array}{c}- \\
0.360\end{array}$ & $\begin{array}{c}- \\
0.296\end{array}$ & $\begin{array}{c}- \\
0.446\end{array}$ & $\begin{array}{c}- \\
0.066\end{array}$ \\
\hline Skewness & $\begin{array}{l}0.47 \\
0\end{array}$ & 1.452 & 0.010 & 1.446 & $\begin{array}{c}- \\
0.212\end{array}$ & 0.249 & 0.633 & 0.718 & 0.871 \\
\hline
\end{tabular}

Note: Standard deviation: $\sigma_{T}=\sqrt{\frac{\sum_{i=1}^{m}\left(z_{i}-\bar{z}\right)^{2}}{m}} i$,Coefficient of Variation:: $c_{v}=\frac{\sigma_{T}}{\bar{z}}$, Kurtosis:

$g_{2}=\frac{\frac{1}{m} \sum_{i=1}^{n}\left(z_{i}-\bar{z}\right)^{4}}{\left(\frac{1}{m} \sum_{i=1}^{n}\left(z_{i}-\bar{z}\right)^{2}\right)^{2}}-3$,Skewness: $s_{k}=\frac{E\left[\left(z_{i}-E\left[z_{i}\right]\right)^{3}\right]}{\sigma_{\text {总 }}^{3}}$. 其中, $z_{i}$ and $\bar{z}$ respectively refer to the resilience of the $i$-th city and the average resilience of all cities, $m$ indicates the number of cities, $E\left[z_{i}\right]$ means the expectation of variable $z_{i}$.

From Table 2, we find the average UR along the YREB's lower reaches from 2010 to 2018 is between 0.350 and 0.480 . The level of UR was not high, and showed an "up-down" trend. Resilience 
a drop of $27.08 \%$ compared with 2014. From 2010 to 2018, the standard deviation of 21 cities resilience ranged from 0.130 to 0.170 , and the coefficient of variation showed a fluctuating growth state, which demonstrates that the resilience of cities along the YREB's lower reaches is different and the spatial difference is expanding. The kurtosis coefficient of cities along the YREB's lower reaches presents a descending tendency from 2010 to 2018, which demonstrates the distribution of UR is gradually concentrated, and the skewness coefficients during the study period are all positive, showing that the proportion of high-grade areas of UR index increases year by year.

\section{Temporal and spatial evolution}

In order to better characterize the development of UR, our paper selects four-time nodes in 2010, 2013, 2016 and 2018, and analyzes the resilience of 21 cities in the temporal-spatial angel.

\section{Temporal evolution}

UR along the YREB's lower reaches from 2010 to 2018 are shown in Fig. 4. The average UR from 2010 to 2018 have a relatively higher-level including Shanghai, Suzhou, Nanjing and Hangzhou. In the past nine years, except for Nanjing, Suzhou, Hefei, and Anqing, which appeared an increasing trend, the resilience values of the remaining cities have gradually declined. Although Anqing's UR increased by $71.12 \%$, which is the highest among all cities, Anqing still has a lower level of UR among 21 cities. It also shows that most cities along the YREB's lower reaches have poor resilience, and the vulnerability of cities are low. Therefore, UR needs to be further enhanced.

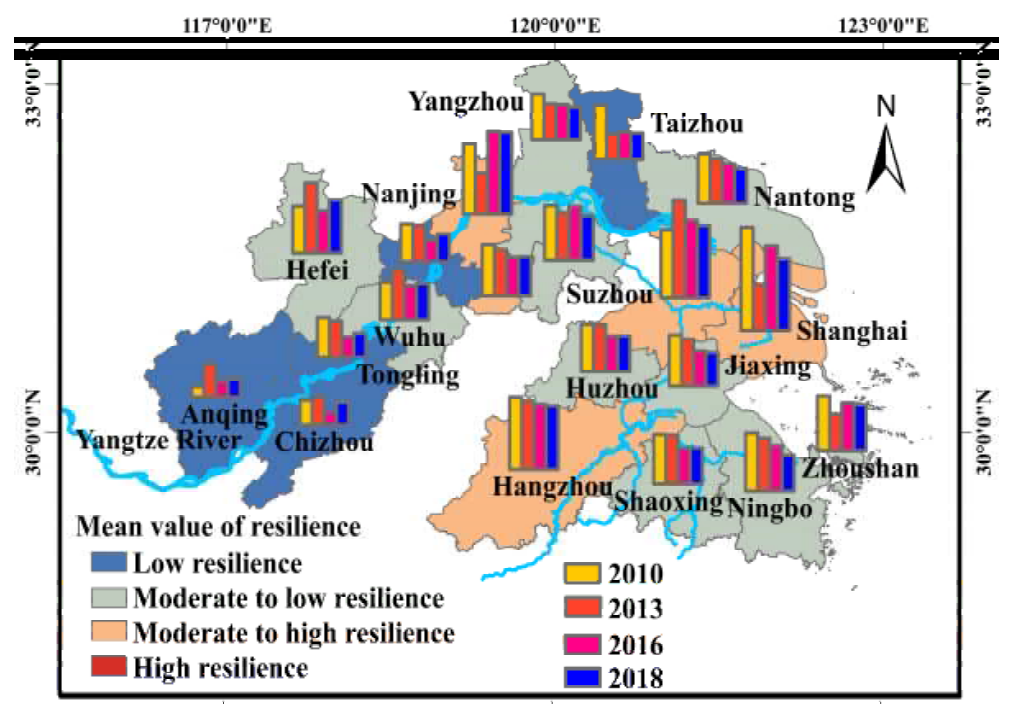

Fig. aaches

In terms of specific time phases, the resilience of Wuxi, Suzhou, Hefei, Wuhu, Anqing and Chizhou has increased from 2010 to 2013, the resilience of other cities such as Shanghai has decreased. Among them Anqing, Hefei and Suzhou had the largest growth rates of $221.87 \%, 50.38 \%$ and $42.85 \%$, while Shanghai became the city with the largest decline rate of 55.55\%. From 2013 to 2016, the UR levels of Shanghai, Nanjing, Changzhou, Taizhou and Zhoushan began to pick up, Shanghai and Nanjing had the largest growth rates, reaching $83.73 \%$ and $102.09 \%$ respectively. From 2016 to 2018, the resilience level of Hefei, Zhenjiang, Wuhu, Ma Anshan, Tongling, Anqing and Chizhou continued to rise. Through the above analysis, we found that (1) central cities such as Shanghai and Nanjing's UR have large fluctuations, indicating that large cities have the fastest resilience due to the perfect infrastructure and social security system after being impacted by the outside world. (2) with the improvement of 
construction, the resilience value of surrounding cities is gradually falling, but the UR is still in the lowlevel even with great development space.

Spatial evolution

Referring to the division standard of UR by Lu et al. (Feiyu et al., 2021) the calculated resilience evaluation is divided into four grades: Low resilience ( $0 \sim 0.30)$, Moderate to low resilience (0.30 0.50), Moderate to high resilience $(0.50 \sim 0.70)$, and high resilience $(0.70 \sim 1.00)$. Then, the comprehensive resilience indexes of 21 cities along the YREB's lower reaches in 2010, 2013, 2016 and 2018 are made using ArcGIS 10.7, which is depicted in Fig. 5.

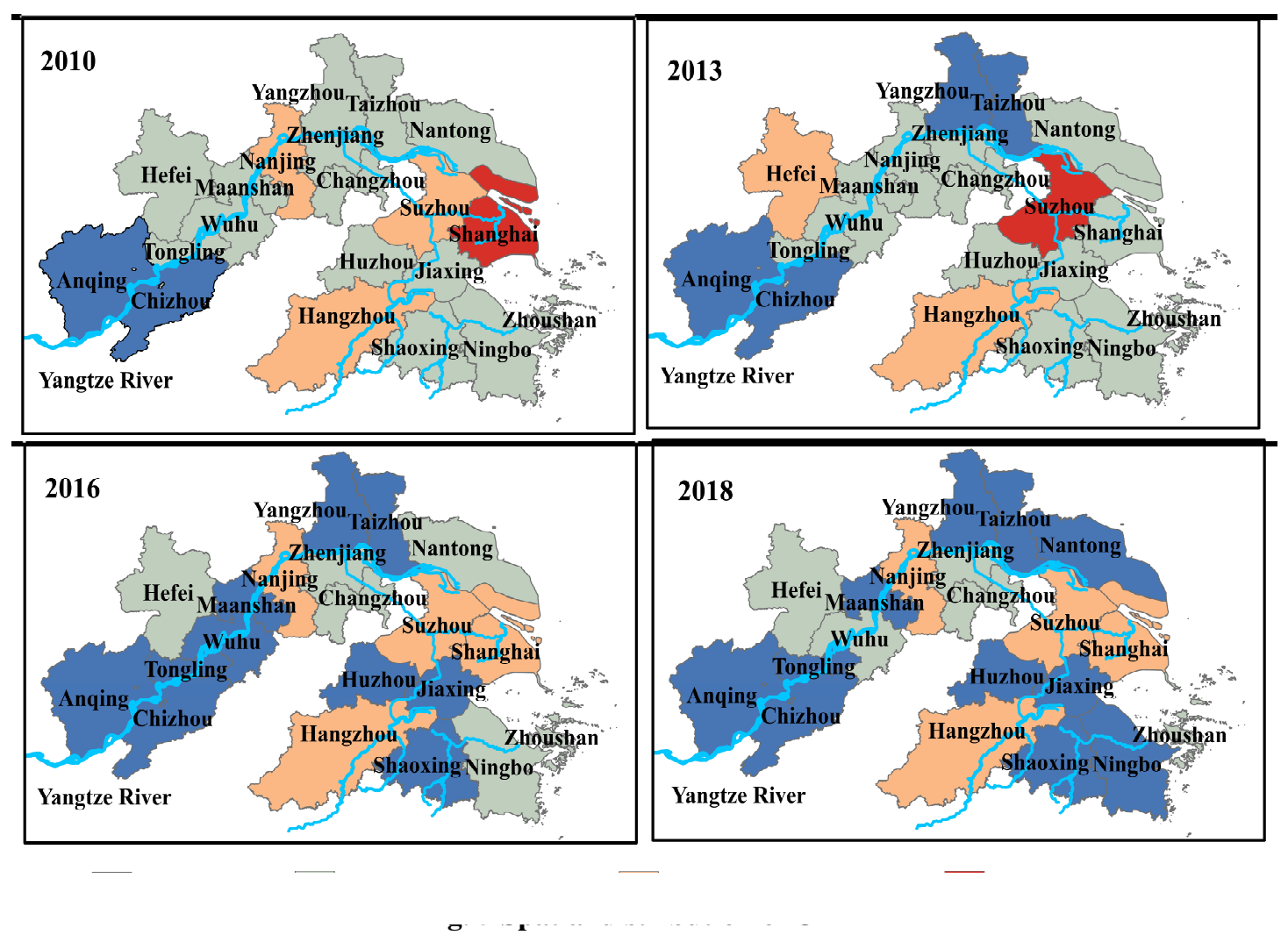

Fig. 5 indicates that UR along the YREB's lower reaches decreases from the provincial capital of each province to the marginal cities. The resilience of central cities is generally high, cities with high resilience are concentrated in Shanghai, Suzhou, Nanjing, Hangzhou and Hefei. Meanwhile, cities with low resilience are becoming much more, which shows a relatively scattered trend.

\section{Drivers of UR}

In order to judge the changes of the driving factors of UR, GD method is used. It could calculate the q value from 2010 to 2018, through comparing the q value in 2018 with that in 2010 to explain the explanatory power of various indicators' changes on the spatial differentiation characteristics of UR. The calculations are presented in the Table 3 .

Table 3 Changes in explanatory power of indicators

\begin{tabular}{cccccccc}
\hline Criterion layer & \multicolumn{3}{c}{ Economy } & \multicolumn{3}{c}{ Water Resources } \\
\hline Index layer & A1 & A2 & A3 & A7 & A8 & A9 & A10 \\
\hline
\end{tabular}




\begin{tabular}{|c|c|c|c|c|c|c|c|}
\hline \multirow{2}{*}{$\begin{array}{c}\text { The change rate } \\
\text { of } q\end{array}$} & $\begin{array}{c}15.892 \\
\%\end{array}$ & $\begin{array}{c}- \\
12.685 \%\end{array}$ & $1.215 \%$ & $\begin{array}{c}137.108 \\
\%\end{array}$ & $\begin{array}{c}- \\
52.840 \%\end{array}$ & $\begin{array}{c}- \\
24.291 \%\end{array}$ & $\begin{array}{c}62.463 \\
\%\end{array}$ \\
\hline & \multicolumn{3}{|c|}{$5.270 \%$} & \multicolumn{4}{|c|}{$30.610 \%$} \\
\hline Criterion layer & \multicolumn{3}{|c|}{ Society } & \multicolumn{4}{|c|}{ Infrastructure } \\
\hline Index layer & A4 & A5 & A6 & A11 & A12 & A13 & A14 \\
\hline \multirow{3}{*}{$\begin{array}{c}\text { The change rate } \\
\text { of } q\end{array}$} & 11.387 & 32.487 & - & 34.315 & 165.283 & 288.971 & 67.572 \\
\hline & $\%$ & $\%$ & $39.849 \%$ & $\%$ & $\%$ & $\%$ & $\%$ \\
\hline & \multicolumn{3}{|c|}{$1.342 \%$} & \multicolumn{4}{|c|}{$139.035 \%$} \\
\hline
\end{tabular}

According to Table 3, compared with 2010, the factor explanatory power of Water Resources and Infrastructure on UR along the YREB's lower reaches gradually increased in 2018, with an average explanatory power increased by $30.610 \%$ and $139.035 \%$ respectively. Among the Infrastructure subsystem, the factor explanatory power of A13 (sickbeds per 10 thousand people) changed the most, with an increase of $288.971 \%$, while in the water resources subsystem, A7 (Domestic sewage centralized treatment rate) increased by $137.108 \%$; the explanatory power of Economy and Society is relatively smaller, with an increase of $5.270 \%$ and $1.342 \%$ respectively.

\section{Discussion}

\section{Comparison of resilience with and without water resources}

In order to better illustrate the changes in UR from the perspective of water resources, our article compares it with UR which is not considering water resources, and selects the results of 2010 and 2018 to study. The results of the research are shown in the Fig. 6.

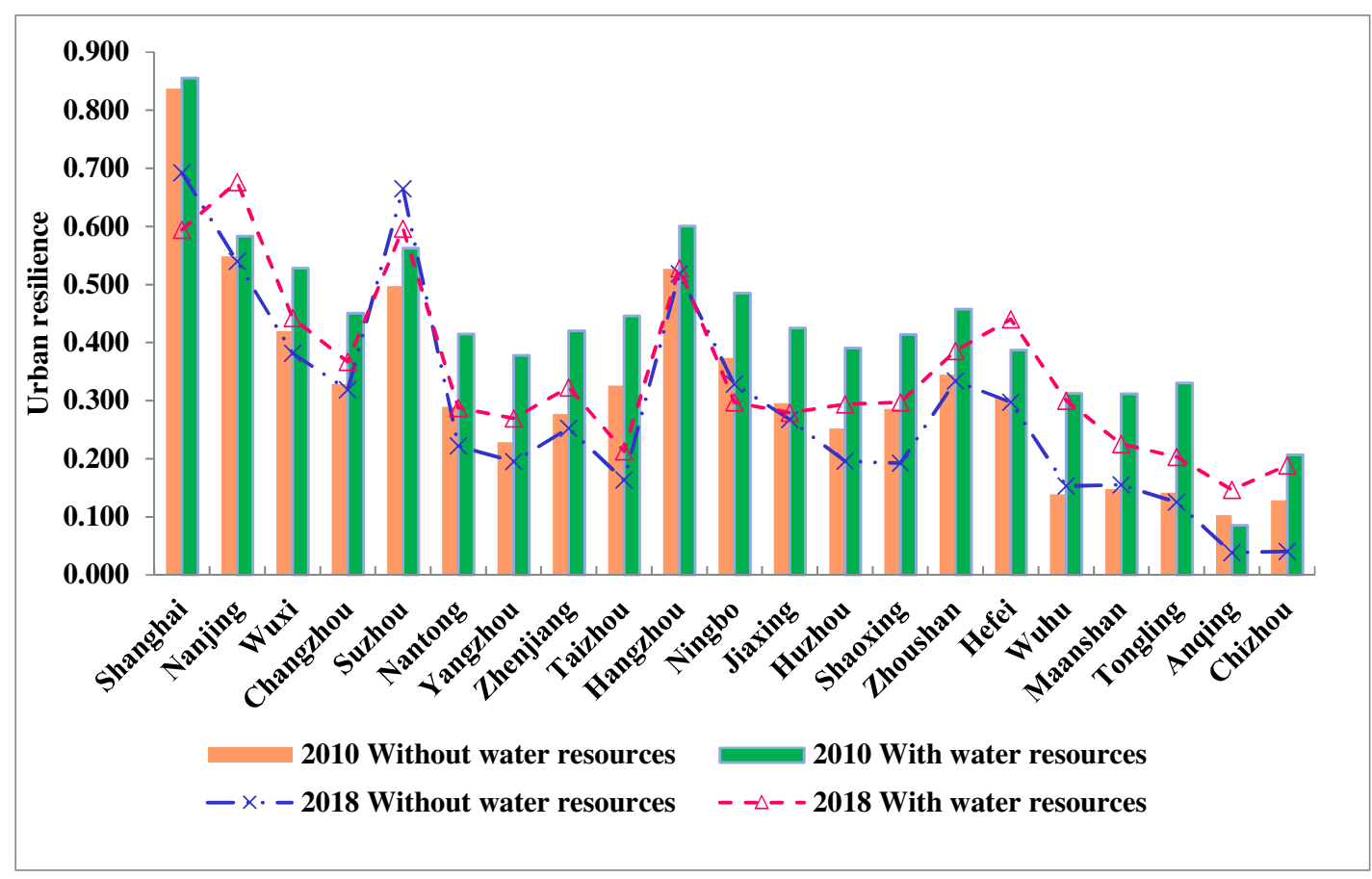

Fig. 6 Comparison of UR with and without water resources

Through comparison, we found that without water resources, UR is significantly lower than that with considering water resources. So, we could say water resources promote the evolution of UR along the YREB's lower reaches. It could conclude that the improvement of water resources utilization 
efficiency in the study area and the remarkable effect of water pollution treatment have promoted the development of water resources and environment, which not only provides a good resource environment for the economy and society, but also promotes the construction of related water conservancy infrastructure, so as to strengthen the overall ability of the city to resist external shocks (Huang et al., 2021). In addition, the resilience of cities along the YREB's lower reaches appears a downward trend on the whole. The reasons may be that as the economy and society developed the industrial evolution of the YREB's lower reaches has increased, the industrialization level has improved, even this area had good water saving technology but its increasing speed lags behind compare with economy and society, which makes the cities unable to respond in time in the face of external disturbances (Cao et al., 2018). It could also see that in the area with sufficient water resources, the efficient utilization of water resources can improve the ability of cities to resist external shocks. However, due to the limited study area, the impact of water resources carrying capacity or utilization efficiency on UR level in drought areas has not been considered.

\section{Grade change of UR}

The change of UR development level along the YREB's lower reaches is shown in Fig. 7.
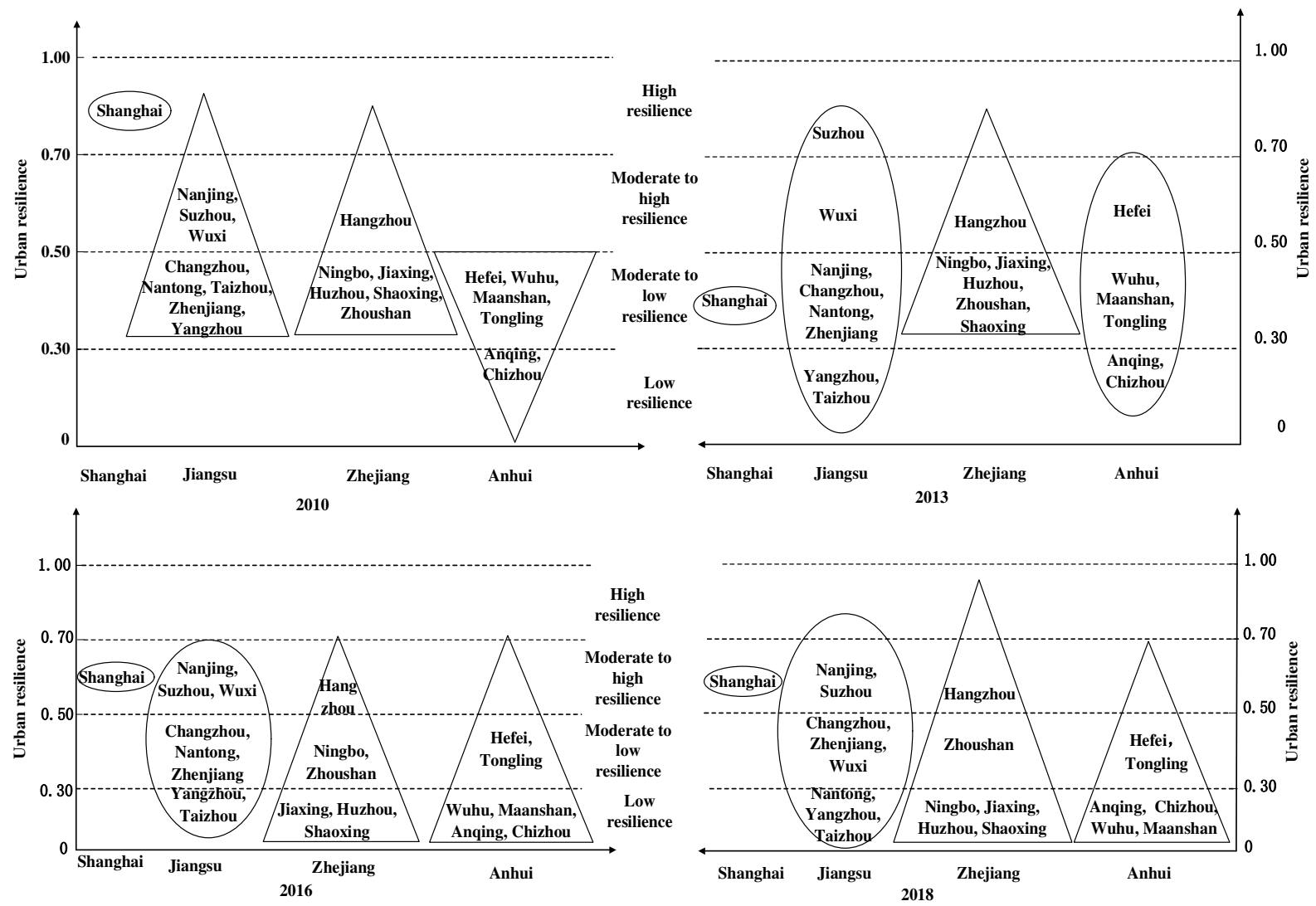

Fig. 7 Resilience grade structure of cities along the YREB's lower reaches

In Fig. 7, the resilience of cities along the YREB's lower reaches presents different hierarchical structures. The hierarchical structures of UR in Shanghai and Zhejiang are a single core and a positive triangle; the change of UR hierarchical structure in Jiangsu is "positive triangle-ellipse-ellipse-ellipse", while the UR in Anhui is "inverted triangle-ellipse-pyramid-positive triangle". From above mapping, we found that the resilience of cities along the YREB's lower reaches from the perspective of water resources 
has the following characteristic. The resilience of cities along the YREB's lower reaches is uneven, and the number of low resilient cities and moderate to low resilient cities is increasing. Due to the "siphon effect" of high resilience cities along of the YREB's lower reaches, the surrounding cities cannot profit from high resilience cities. At the same time, rich resources and environment are also attracted and gathered by high resilience cities, which causes certain damage to the ability of low resilience cities to resist external shocks (Wang et al., 2020). It makes the difference of resilience level between cities larger and larger. Therefore, the resilience level of cities along the river has significant spatial heterogeneity.

\section{Driving factors analysis}

According to the exploration of urban driving factors by GD method, our paper draws the following heat map (Fig. 8) to analyze the change of explanatory power of each driving factor on UR in the four subsystems of "Economy-Society-Infrastructure-Water Resources" from 2010 to 2018.

\begin{tabular}{|c|c|c|c|c|c|c|c|c|c|c|c|c|c|c|}
\hline \multirow{2}{*}{2010} & $\mathrm{~A} 1$ & A2 & $\mathrm{A} 3$ & A4 & A5 & A6 & A7 & A8 & A9 & A 10 & Al1 & A12 & A13 & A14 \\
\hline & & & & & & & & & & & & & & \\
\hline \multicolumn{15}{|l|}{2011} \\
\hline \multicolumn{15}{|l|}{2012} \\
\hline \multicolumn{15}{|l|}{2013} \\
\hline \multicolumn{15}{|l|}{2014} \\
\hline \multicolumn{15}{|l|}{2015} \\
\hline \multicolumn{15}{|l|}{2016} \\
\hline 2017 & & & & & & & & & & & & & & \\
\hline 2018 & & & & & & & & & 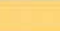 & & & & & \\
\hline
\end{tabular}

Fig. 8 Spatial differentiation of UR along the YREB's lower reaches

Fig. 8 draws that among the four subsystems, economic resilience and social resilience have relatively less influence. Firstly, the influence of per capita GDP in the economic dimension changes little, while the explanatory power of the detection factor of the proportion of SI and TI in GDP tends to increase. A reasonable industrial structure can improve the economic benefits of the city, develop the regional social economy, and then provide a firm economic base in order to strengthen the city to withstand external shocks. Nonetheless, our study found that the industrial structure between cities along the YREB's lower reaches is required to be optimized, and TI's development needs to continue to increase (Cui et al., 2021). Secondly, education investment symbols the development potential of the city from the perspective of social development (Yang et al., 2021a), and wage income indicates the development status of the city. The more unbalanced the investment in education and residents' income, the ability to resist external shocks will be weaker (Hahn et al., 2017; Lewin et al., 2018). During the study period, the investment in education and the number of college students in cities along the YREB's lower reaches increased year by year, which improved the ability of lifelong learning of community people, and improved the ability of cities to overcome difficulties and resist risks further. As the economic center of the YREB, the economic level and social development capacity of cities along the lower reaches have improved year by year, which has promoted the improvement of economic scale and social richness. When these cities developed into a phase, the influence of economic resilience and social resilience on cities has gradually weakened.

The impact of infrastructure resilience and water resources resilience is relatively larger. Specifically, from the perspective of infrastructure, with the advance of time, the explanatory power of detection factors of urban infrastructure subsystems such as highway passenger volume and sickbeds per 10 
thousand people gradually increases. The research shows that the sophisticated urban infrastructure plays a positive character in the sustainable development of economy and society, and can also improve the utilization efficiency of resources. Hence, the impact of infrastructure on UR tends to increase when subjected to external shocks (Wang et al., 2018). In addition, in the water resources resilience, the explanatory power of residents' water-saving efficiency, sewage and wastewater treatment on UR increases year by year, which indicates that they have a crucial impact on improving the risk resistance of cities (Matthews et al., 2016; Rushforth et al., 2020; Yang et al., 2020). However, due to the large population and intensive resource consumption, the city is facing difficulties such as the lack of balance both supply and demand of water resources and the finite bearing capacity of water environment, which weakens the city' power when facing external shocks (Zhu and Chang, 2020).

All in all, as the economy boosts substantially, cities along the YREB's lower reaches are facing pressure in infrastructure construction and the improvement of water resources system. Therefore, when the cities are in the proceeding of resilience development, not only should we have an eye on the improvement of urban economic capacity, but also emphasize the development of urban infrastructure and water resources.

\section{Conclusions and Suggestions}

\section{Conclusions}

Improving the development of UR is essential to enhance the ability of cities to resist external shocks. Based on the framework of "Economy-Society-Infrastructure-Water Resources", our paper constructs IS to study UR along the YREB's lower reaches, measures its resilience and driving factors. The conclusions are as follows:

(1) From 2010 to 2018, the resilience value of cities along the YREB's lower reaches was not high and the average value showed a downward trend. Among the 21 cities, Shanghai has the highest average resilience (0.651), while Chi Zhou has the lowest average resilience (0.178). Nanjing, Suzhou and Hangzhou have always been moderate to high resilience, while Shanghai has decreased from high resilience to moderate to high resilience. The UR of each province decays from the central city to the edge city.

(2) Compared with cities without water resource, cities' resilience with consider water resource are significantly higher. This shows that the existence of water resources promotes the resilient development of cities along the YREB's lower reaches.

(3) Compared with 2010, the spatial diversity of UR along the YREB's lower reaches in 2018 was mainly affected by water resources and infrastructure subsystems, the average explanatory power of factors increased by $30.610 \%$ and $139.035 \%$ respectively; the explanatory powers of economic and social dimension are relatively smaller, with an increase of $5.270 \%$ and $1.342 \%$ respectively.

\section{Suggestions}

Based on above analysis, if cities along the YREB's lower reaches increase UR, following suggestions should be put forward.

Government should concentrate on improving the level of residents' water-saving and current situation of urban water resources management. Since explanatory power of water resources increases gradually, cities along the YREB's lower reaches related department should pay attention to the water resource utilization efficiency of urban residents, accurately grasp that of each city, actively improve 
urban water-saving technology, promote the construction and development of water-saving cities. At the same time, the water conservancy department should improve the resilience of urban water resources, focus on making the imbalance both supply and demand of water resources and the carrying capacity of water environment get better, and pay attention to improving the function of regional water resources regulation.

The resilience of cities along the YREB's lower reaches is uneven. In order to actively respond to the challenges brought by external shocks, the urban governments along the YREB's lower reaches need to speed up the proceeding of regional development integration and intensify the radiation and driving role of central cities such as Shanghai, Nanjing, Hangzhou and Hefei, so as to drive the surrounding cities' resilience enhancing. Furthermore, in order to promote the transformation from competition to cooperation between cities, the urban governments should also give full play to local advantages and form regional division of labor, promote the diversification of industrial structure, vigorously develop high-tech industries, constantly optimize the industrial structure of cities.

Labor department should balance residents' wage income and improve the guarantee ability of urban public resources. They should promote the common prosperity of the whole society by expanding middleincome groups and improving income distribution. At the same time, relevant departments should better the level of infrastructure, accelerate the construction of resilient cities along the YREB's lower reaches, and strengthen the dynamic monitoring capacity of infrastructure. Besides, the construction and development of urban transportation and medical facilities are should be paid more attention. Finally, in order to ensure appropriate redundancy of emergency facilities, it is essential to improve the construction of regional transportation system and emergency infrastructure and set up reasonable standby mechanism to effectively disperse risks. 
Min An: Supervision Validation; Mengfei Song: Conceptualization, Methodology, Writing-original draft; Jin Huang: Conceptualization, Software; Weijun He: Writing-reviewing and editing; Xue Fang: Data curation. All authors commented on previous versions of the manuscript, and all authors read and approved the final manuscript.

483

\section{Ethical approval}

This manuscript was only submitted on Environmental Science and Pollution Research. And the authors make sure they have permissions for the use of software, questionnaires/(web) surveys and scales in their studies (if appropriate). This research may not be misapplied to pose a threat to public health or national security. There was no animal experiment in this manuscript.

\section{Consent to participate}

Results in this manuscript were presented clearly, honestly, and without fabrication, falsification or inappropriate data manipulation (including image based on manipulation).

\section{Consent to publish}

493 All co-authors have seen and approved the manuscript and have agreed to its submissions for publication. 


\section{References}

Abdul Majeed A S, Melissa T, Ashantha G, M. Z A (2018) An inclusive and adaptive fram ework for measuring social resilience to disasters. International Journal of Disaster Risk Reduct ion 28, 862-873.https://doi.org/10.1016/j.ijdrr.2018.02.004

Abdul Majeed A S, Teo M, Goonetilleke A, Ziyath A M, Nianthi K W G (2020) Surrogate Measures to Assess Mobility of People as a Resilience Indicator in Disaster Management: An Exploratory Study in Southeastern Sri Lanka. International Journal of Disaster Risk Science 11, 13-31.https://doi.org/10.1007/s13753-020-00251-4

Adger W N (2000) Social and ecological resilience: are they related? Progress in Human Ge ography 24, 347-364.https://doi.org/10.1191/030913200701540465

Aydemir M E, Gunel T, Erer I, Kurnaz S (2003) A novel approach for synthetic aperture ra dar image processing based on genetic algorithm. Journal, 365-368.https:// doi. org/10.1109/RAS T.2003.1303944

Bjornskov C (2016) Economic freedom and economic crises. European Journal of Political E conomy 45, 11-23.https://doi.org/10.1016/j.ejpoleco.2016.08.003

Cabezon E, Hunter L, Tumbarello P, Washimi K, Wu Y (2015) Enhancing Macroeconomic R esilience to Natural Disasters and Climate Change in the Small States of the Pacific. Asian-Pac ific Economic Literature 33, 113-130. https://doi.org/10.1111/apel.12255

Cao W, Yuan R, Business S O, University H (2018) Analysis on the Efficiency of Water C onservancy Investment in the Yangtze River Economic Belt. Journal of Wuhan University of $\mathrm{T}$ echnology(Information \& Management Engineering) 40, 450-454.https://kns.cnki.net/kcms/detail/de tail.aspx?FileName $=$ WHQC201804017 $\&$ DbName $=$ CJFQ2018

Childers D L, Cadenasso M L, Grove J M, Marshall V, McGrath B, Pickett S T A (2015) An Ecology for Cities: Transformational Nexus of Design and Ecology to Advance Resilience and Urban. Sustainability 7, 3774-3791.https://doi.org/10.3390/su7043774

Cui X, Wu J, Li Z, Peng L, Shen Z, Bi J (2021) An Integrated Assessment and Factor An alysis of Water Related Environmental Risk to Cities in the Yangtze River Economic Belt. Wat er 13, 2140.https://doi.org/10.3390/w13162140

Cutter S L, Barnes L, Berry M, Burton C, Evans E, Tate E, Webb J (2008) A Place-Based Model for Understanding Community Resilience to Natural Disasters. Global Environmental Ch ange 18, 598-606.https://doi.org/10.1016/j.gloenvcha.2008.07.013

Davies S (2011) Regional resilience in the 2008--2010 downturn: comparative evidence from European countries. Cambridge Journal of Regions Economy\&Society 4, 369-382.https://doi.org/ $\underline{10.1093 / \text { cjres/rsr019 }}$

Deyou M, Yuqi L, Xinsheng F, Benlin S (2013) Evaluation of county traffic and economic coordination in Henan Province Based on Projection Pursuit Model. Geographical research 32, 2092-2106.https://kns.cnki.net/kcms/detail/detail.aspx?FileName=DLYJ201311012\&DbName=CJFQ2 $\underline{013}$

Du S, He C, Huang Q, Shi P (2018) How did the urban land in floodplains distribute and expand in China from 1992-2015? Environmental Research Letters 13, 034018.http://doi.org/10. $\underline{1088 / 1748-9326 / \mathrm{aaac} 07}$

Fang C L, Xie Y (2010) Sustainable urban development in water-constrained Northwest Chin 
a: A case study along the mid-section of Silk-Road- He-Xi Corridor. Journal of Arid Environ ments 74, 140-148.https://doi.org/10.1016/j.jaridenv.2009.07.009

Feiyu L, Weihua Y, Nannan L (2021) Study on temporal and spatial evolution and influenci ng factors of industrial toughness of urban agglomeration in Yangtze River Delta. World Regio nal Studies 30, 589-600.https://kns.cnki.net/kcms/detail/detail.aspx?FileName=SJDJ202103014\&Db $\underline{\text { Name}=D K F X 2021 ~}$

Fu Q, Xie Y G, Liu S Y (2003) Projection pursuit evaluation model based on accelerating genetic algorithm to optimize irrigation schedules. Journal of Experimental Botany 54, i32-i46.h ttps://doi.org/10.1093/oxfordjournals.jxb.a003382

Goncalves L A P J, Ribeiro P J G (2020) Resilience of urban transportation systems. Conce pt, characteristics, and methods. Journal of Transport Geography 85.http://doi.org/10.1016/j.jtrang $\underline{\text { eo.2020.102727 }}$

Hahn D, Willis T L, Christie A R, Mathews S R (2017) The relationship between social ca pital and potential resilience in individuals. Journal of emergency management (Weston, Mass.) 15, 189-194.http://doi.org/10.5055/jem.2017.0327

Huang C, Yin K, Liu Z, Cao T (2021) Spatial and Temporal Differences in the Green Effici ency of Water Resources in the Yangtze River Economic Belt and Their Influencing Factors. I nternational Journal of Environmental Research Public Health 18, 3101.http://doi.org/10.3390/IJE $\underline{\text { RPH18063101 }}$

Koc K, Isik Z (2021) Assessment of Urban Flood Risk Factors Using Monte Carlo Analytic al Hierarchy Process. Natural Hazards Review 22, 14.http://doi.org/10.1061/(asce)nh.1527-6996.0 $\underline{000516}$

Lewin P A, Watson P, Brown A (2018) Surviving the Great Recession: the influence of inco me inequality in US urban counties. Regional Studies 52, 781-792.http://doi.org/10.1080/003434 $\underline{04.2017 .1305492}$

Li G (2021) Construction concept and practice path of resilient City. People's Tribune, 86-89. https://kns.cnki.net/kcms/detail/detail.aspx?FileName=RMLT202125021\&DbName=CJFQ2021

Li J, Chen Y D, Zhang L, Zhang Q, Chiew F H S (2016) Future Changes in Floods and Water Availability across China: Linkage with Changing Climate and Uncertainties. Journal of Hydrometeorology 17, 1295-1314.http://doi.org/10.1175/jhm-d-15-0074.1

Li L, Wang W (2020) Research on spatial heterogeneity of China's manufacturing developme nt quality-Analysis Based on Projection Pursuit Model. East China Economic Management v.34; No.285, 1-11.http://doi.org/10.19629/j.cnki.34-1014/f.200328008

Ma F, Wang Z H, Sun Q P, Yuen K F, Zhang Y X, Xue H F, Zhao S M (2020) Spatial-Te mporal Evolution of Urban Resilience and Its Influencing Factors: Evidence from the Guanzhon g Plain Urban Agglomeration. Sustainability 12.http://doi.org/10.3390/su12072593

Martin R, Gardiner B(2019) The resilience of cities to economic shocks: A tale of four rece ssions (and the challenge of Brexit). Papers in Regional Science.http://doi.org/10.1111/pirs.12430

Masnavi M R, Gharai F, Hajibandeh M (2019) Exploring urban resilience thinking for its ap plication in urban planning: a review of literature. International Journal of Environmental Scien ce and Technology 16, 567-582.http://doi.org/10.1007/s13762-018-1860-2

Matthews E C, Friedland C J, Orooji F (2016) Integrated environmental sustainability and re 
silience assessment model for coastal flood hazards. Journal of Building Engineering 8, 141-15 1.http://doi.org/10.1016/j.jobe.2016.08.002

Meerow S, Newell J, Stults M (2016) Defining urban resilience: A review. Landscape and U rban Planning 147, 38-49.http://doi.org/10.1016/j.landurbplan.2015.11.011

Moghadas M, Asadzadeh A, Vafeidis A, Fekete A, Kotter T (2019) A multi-criteria approach for assessing urban flood resilience in Tehran, Iran. International Journal of Disaster Risk Red uction 35.http://doi.org/10.1016/j.ijdrr.2019.101069

Rose A (2004) Defining and Measuring Economic Resilience to Disasters. Disaster Preventio $\mathrm{n}$ and Management 13, 307-314.http://doi.org/10.1108/09653560410556528

Rushforth R R, Messerschmidt M, Ruddell B L (2020) A Systems Approach to Municipal Water Portfolio Security: A Case Study of the Phoenix Metropolitan Area. Water 12.http://doi.o rg/10.3390/w12061663

Shamsuddin S (2020) Resilience resistance: The challenges and implications of urban resilien ce implementation. Cities 103, 102763.https://doi.org/10.1016/j.cities.2020.102763

Tan J, Zhang P, Kevin L O, Jing L I, Liu S (2017) Conceptualizing and measuring economi c resilience of resource-based cities: Case study of Northeast China. Chinese Geographical Scie nce 27, 471-481.https://doi.org/10.1007/s11769-017-0878-6

Wang J, Xu C (2017) Geographic Detector: Principle and Prospect. Journal of Geography 72, 116-134.https://doi.org/10.11821/dlxb201701010

Wang L, Xue X, Wang Z, Zhang L (2018) A Unified Assessment Approach for Urban Infra structure Sustainability and Resilience. Advances in Civil Engineering 2018, 2073968.http://doi.o rg/10.1155/2018/2073968

Wang X W, Ding S L, Cao W D, Fan D L, Tang B (2020) Research on Network Patterns and Influencing Factors of Population Flow and Migration in the Yangtze River Delta Urban A gglomeration, China. Sustainability 12.http://doi.org/10.3390/su12176803

Wei Y X, Zhao Y Y, Wang X Y (2012) Optimization of Corn Furrow Irrigation Modes Bas ed on RAGA-PPC Model. Journal 308, 561-566.https://doi.org/10.1007/978-3-642-34041-3_78

Won K, Chung E-S, Kim Y, Hong I (2014) Assessment of Water Resources Vulnerability In dex by Nation. Journal of Korea Water Resources Association 47.http://doi.org/10.3741/JKWRA. $\underline{2014.47 .2 .183}$

Wu T (2021) Quantifying coastal flood vulnerability for climate adaptation policy using princ ipal component analysis. Ecological Indicators 129.http://doi.org/10.1016/j.ecolind.2021.108006

Xin Q, Jingshuai Z, Weixiang X (2019) Study on the evaluation of county economic resilien ce development in Zhejiang Province. Zhejiang Social Sciences, 40-46+156.https://kns.cnki.net/kc $\underline{\text { ms/detail/detail.aspx?FileName=ZJSH201905005\&DbName }=\text { CJFQ2019 }}$

Xu H, Li Y, Tan Y T, Deng N H (2021) A Scientometric Review of Urban Disaster Resilie nce Research. International Journal of Environmental Research and Public Health 18, 27.http://d oi.org/10.3390/ijerph18073677

Yan D, Feng J, Li C, Qin T, Weng B, Jin X (2012) General framework and key issues con cerning integrated strategies for coping with drought and flood in China in a changing environ ment. Natural Hazards 64.http://doi.org/10.1007/s11069-012-0258-6

Yang Y, Fang Y, Xu Y, Zhang Y (2021a) Assessment of urban resilience based on the trans 
formation of resource-based cities: a case study of Panzhihua, China. Ecology and Society 26.h ttp://doi.org/10.5751/ES-12280-260220

Yang Y, Wang H, Gong S, Deng C (2021b) Variable Pythagorean fuzzy VIKOR evaluation r egulation model of water resources system resilience and its application. Journal of Hydraulic Engineering 52, 633-646.http://doi.org/10.13243/j.cnki.slxb.20200455

Yang Y Y, Guo H X, Chen L F, Liu X, Gu M Y, Pan W W (2020) Multiattribute decision making for the assessment of disaster resilience in the Three Gorges Reservoir Area. Ecology and Society 25.http://doi.org/10.5751/es-11464-250205

Yin C (2020) Hazard assessment and regionalization of highway flood disasters in China. Na tural Hazards 100.http://doi.org/10.1007/s11069-019-03824-9

Zhang H M, Yang J Y, Li L S, Shen D Y, Wei G, Khan H U R, Dong S J (2021) Measur ing the resilience to floods: A comparative analysis of key flood control cities in China. Intern ational Journal of Disaster Risk Reduction 59.http://doi.org/10.1016/j.ijdrr.2021.102248

Zhang M M, Chen W G, Cai K, Gao X, Zhang X S, Liu J X, Wang Z Y, Li D S (2019) Analysis of the Spatial Distribution Characteristics of Urban Resilience and Its Influencing Fact ors: A Case Study of 56 Cities in China. International Journal of Environmental Research and Public Health 16, 22.http://doi.org/10.3390/ijerph16224442

Zhao R D, Fang C L, Liu H M, Liu X X (2021) Evaluating urban ecosystem resilience usi ng the DPSIR framework and the ENA model: A case study of 35 cities in China. Sustainable Cities and Society 72, 11.http://doi.org/10.1016/j.scs.2021.102997

Zhao X, Zhou W, Han L (2019) Human activities and urban air pollution in Chinese mega city: An insight of ozone weekend effect in Beijing. Physics and Chemistry of the Earth, Parts A/B/C 110, 109-116.http://doi.org/10.1016/j.pce.2018.11.005

Zhou K, Liu B, Fan J (2020) Post-earthquake economic resilience and recovery efficiency in the border areas of the Tibetan Plateau: A case study of areas affected by the Wenchuan Ms 8.0 Earthquake in Sichuan, China in 2008. Journal of Geographical Sciences 30, 1363-1381.htt p://doi.org/10.1007/s11442-020-1786-8

Zhu D, Chang Y-J (2020) Urban water security assessment in the context of sustainability a nd urban water management transitions: An empirical study in Shanghai. Journal of Cleaner Pr oduction 275, 122968.https://doi.org/10.1016/j.jclepro.2020.122968

Zhu H, Zhu J, Zou Q (2020) Comprehensive Analysis of Coordination Relationship between Water Resources Environment and High-Quality Economic Development in Urban Agglomeratio $\mathrm{n}$ in the Middle Reaches of Yangtze River. 12, 1301.http://doi.org/10.3390/w12051301 


\section{Statements \& Declarations}

655 Funding

656 This work was supported by the National Science Foundation of China (No.72004116, 71874101,

657 72104127); Hubei Social Science Foundation: Research on Optimal Allocation and Guarantee Measures

658 of Trans-regional Water Pollution Load in the Yangtze River Economic Zone (No. 2020051); Hubei

659 Province Humanities and Social Sciences Key Research Base Project: An Empirical Study on the

660 Evaluation of Urban-rural Integration Development and Spatial Pattern Evolution in Chongqing Western

661 Region (2021-SDSG-05); 2021 Hubei Provincial Department of Education Science Research Program

662 Funded Project for Young and Middle-aged Talents: Characteristics and driving factors of carbon

663 emissions spatial-temporal transfer network in China (No.Q20211211).

664 Completing Interests

665 The authors have no relevant financial or non-financial interests to disclose.

666 Data availability

667 Data associated with the present study can be accessed on request to the author (huangjin@ctgu.edu.cn). 